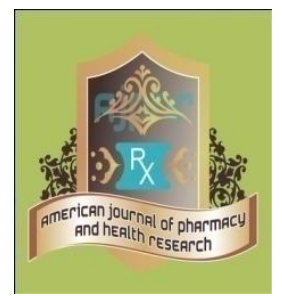

\title{
Peroxisome Proliferator-Activated Receptors: A New Ray Of Hope For Parkinson's Disease
}

\author{
Rohit Bhatt, Sachin Parmar* \\ Department of Pharmaceutical Sciences, Saurashtra University, Rajkot-360005, Gujarat, India.
}

\section{ABSTRACT}

$\mathrm{PD}(\mathrm{PD})$ is a debilitating progressive age-related neurodegenerative disorder that negatively impacts bodily movement. It is the second most common type of neurodegenerative disease after Alzheimer's disease. Although the etiology and pathogenesis of PD remain unknown, a vast body of evidence indicates that oxidative stress, inflammation, apoptosis, mitochondrial dysfunction, and proteasomal dysfunction all play a role in the disease's pathogenesis. Because of the multifactorial nature of the disease, current drug treatment can only offer symptomatic relief and cannot stop or delay the disease progression. The Peroxisome proliferator-activated receptors (PPARs) are the member of the receptor's superfamily called, nuclear receptors, regulates the growth, differentiation of the tissues, inflammation, mitochondrial function, wound healing, lipid metabolism, and glucose metabolism. Several PPAR agonists have recently been shown to protect neurons from oxidative damage, inflammation, and apoptosis in Alzheimer's disease, PD, Huntington's disease, amyotrophic lateral sclerosis, and multiple sclerosis. We review the research on the neuroprotective effects of PPAR agonists in in-vitro and in-vivo models of PD in this paper. Similarly, the pharmacological mechanism of PPAR agonists' neuroprotective effects is examined. Finally, PPAR agonists exert neuroprotective effects by controlling the expression of a set of genes involved in cell survival processes, suggesting that they may be a potential therapeutic target in crippling neurodegenerative diseases like PD.

Keywords: Parkinson's disease, neuroprotective, neuro inflammatory, oxidative stress, PPAR agonist 


\section{INTRODUCTION}

PD is a second common neurodegenerative disease that occurs due to the loss of dopaminergic neurons in the substantia nigra in the brain. PD affects more than 6 million people globally and is expected to multiple two-fold in the next decade (1). The signs of PD range from tremors to stiffness and also cognitive dysfunction. Dopaminergic medications that compensate for the lack of dopamine (DA) in the brain are the primary treatment choices. Replacement of DA with LDopa, DA agonists, and enzyme blockers for MAO-B and COMT can reverse L-Dopa treatment complications such as dyskinesis and motor response oscillations (2,3). Moreover, many of the non-motor PD symptoms can be alleviated by multiple therapeutic options available currently (4). Non-pharmacological therapies based on physical exercise, support the therapeutic armamentarium, which halts serious impairments over many years and maintains the quality of life for most patients.

However, despite all symptomatic PD therapy refined over the past decades, none of the drugs currently available have been shown to slow down or inhibit the development of the disorder. In long-term, most PD patients will suffer significant impairments in motor and non-motor function and reach the key features such as postural instability, serious dysarthria and dysphagia, orthostatic symptoms, urinary preservation and/or incontinence, and dementia and hallucinosis as well as cognitive decline $(3,5,6)$.

Treatment options are very limited for all such late-stage complications, and management of those in PD patients is an urgent unmet need. New clinical goals and medicines must therefore be developed urgently to address the unmet need for a safe and effective disease-modifying therapy option for PD.

\section{PATHOLOGICAL MECHANISMS INVOLVED IN PARKINSON'S DISEASE}

Increased oxidative stress (7), mitochondrial dysfunction (8), apoptosis (9), neuroinflammation (10), excitotoxicity (11), and abnormal protein aggregation/proteasomal dysfunction $(12,13)$ are proposed cellular mechanisms responsible for idiopathic PD.

\section{Oxidative stress}

Since endogenous DA undergoes both enzymatic and nonenzymatic oxidative metabolism, resulting in the formation of reactive oxygen species (ROS) in the SN, oxidative stress has received the most attention in $\mathrm{PD}$ pathogenesis among the many pathogenic mechanisms thought to lead to the demise of DA neurons in PD $(7,14)$. Increased iron, decreased GSH, increased levels of the lipid peroxidation product malondialdehyde, and oxidative damage to lipids and proteins have all been found in post-mortem studies of PD brains, implying that oxidative stress 
plays a role in the disease (15-20). Similarly, increased expression of the DNA repair by enzyme 8-oxoguanine DNA glycosylase (OGG1) in the SN of PD patients suggests increased DNA oxidation in the disease (17,21). Furthermore, cytoplasmic 8-hydroxyguanosine (8OHG; a typical result of nucleic acid oxidation) immunoreactivity was found to be significantly higher in the SN of PD patients as compared to age-matched controls.

\section{Mitochondrial dysfunction}

A significant body of evidence indicates that mitochondrial function is impaired in PD $(22,23)$. The discovery of a synthetic opiate, 1-methyl-4-phenyl-1,2,3,6-tetrahydrodropyridine (MPTP), which was found to induce parkinsonism in drug-addicted young people, provided the most convincing evidence of mitochondrial dysfunction in PD. In glial cells, MPTP is converted to $\mathrm{MPP}+$, which is preferentially taken up by DA neurons and inhibits complex I of the electron transport chain, resulting in neuronal death (24). Platelets, SN, and skeletal muscle of PD patients had lower mitochondrial complex-I activity (25-28). Similarly, cybrids containing mitochondrial DNA from PD patients have lower complex-I activity and are more vulnerable to $\mathrm{MPP}+$ (29). As a result, the mitochondrial complex-I defect can play a role in PD cell degeneration by reducing ATP synthesis and causing a bioenergetic defect. Several studies have also shown the function of a mitochondrial complex-I defect in the pathogenesis of PD. Other complex-I inhibitors, such as rotenone and paraquat, were found to cause oxidative damage to dopaminergic neurons in the SN and cultured DA neurons, similar to MPTP, indicating that mitochondrial dysfunction plays a role in PD pathogenesis (30,31). Several studies have shown the existence of mutations in mitochondrial DNA (mtDNA) in addition to the mitochondrial complex-I deficiency. Mutations in mtDNA polymerase gamma have recently been discovered in five ethnically diverse Finnish families, and they have been identified as a major cause of inherited neurodegenerative diseases (32).

Recently, a fascinating study found that mouse SN DA neurons have lower mitochondrial mass than non-DA neurons, indicating that these neurons are more vulnerable to mitochondrial dysfunction in PD (33).

\section{Apoptosis and neuroinflammation}

The pathogenesis of PD is complicated by neuroinflammation and apoptosis. Apoptosis and autophagy have been observed in postmortem PD brains (9). In PD patients' dopaminergic neurons, elevated nuclear translocation of NF-kB was also reported (34). Apoptosis and inflammation in the parkinsonian brain are also suggested by altered expression of pro-apoptotic genes, elevated levels of p53 protein, interferon-gamma, and NF-kB, and stimulation of caspases 
in the SN of PD patients (35-40). Microglia that have been activated have been found in the SN of PD patients, where they release interleukins, interferon, and tumor necrosis factor- $\alpha$, all of which cause apoptosis $(41,42)$. In PD, synuclein accumulation induces microglial activation, which results in chronic and progressive nigral neurodegeneration (43). While the triggers for microgliosis in PD are unclear, neuromelanin-containing DA neurons are more susceptible to neuroinflammation in the disease. Furthermore, it is unclear if neuroinflammation is a primary cause of PD or merely a side effect of the disease.

\section{Proteasomal dysfunction}

Proteasomal dysfunction leads to an accumulation of misfolded proteins, which eventually leads to neuronal death. Parkin, a-synuclein, DJ-1, and UCH-L1 gene mutations indicate a role for proteasomal dysfunction in the pathogenesis of PD (44). In the SN of post-mortem tissue from PD patients, there was confirmed proteasomal dysfunction/reduced proteasomal activity $(12,45)$. In PD patients, selective loss of the $20_{\mathrm{S}}$ proteosome a-subunit has also been documented in the SN (13). Lactacystin (a selective proteosome inhibitor) injections into the striatum resulted in increased levels of heme oxygenase-1, alpha-synuclein accumulation, and retrograde neuronal degeneration in the $\mathrm{SN}$, indicating a role for proteasomal dysfunction in PD (46).

\section{PEROXISOME PROLIFERATOR-ACTIVATED RECEPTORS: FUNCTION AND PHARMACOLOGY}

PPARs are nuclear receptor superfamily transcription factors that are activated by ligands (47) (Figure 1). PPARs have three isoforms $(\alpha, \beta / \delta$, and $\gamma$ ), each with different physiological and pharmacological roles depending on their target genes and tissue distribution $(48,49)$. Indeed, natural ligands such as fatty acids and eicosanoid derivate, as well as synthetic ligands (lipidlowering fibrates), activate PPAR, which regulates lipid and lipoprotein metabolism (50). 


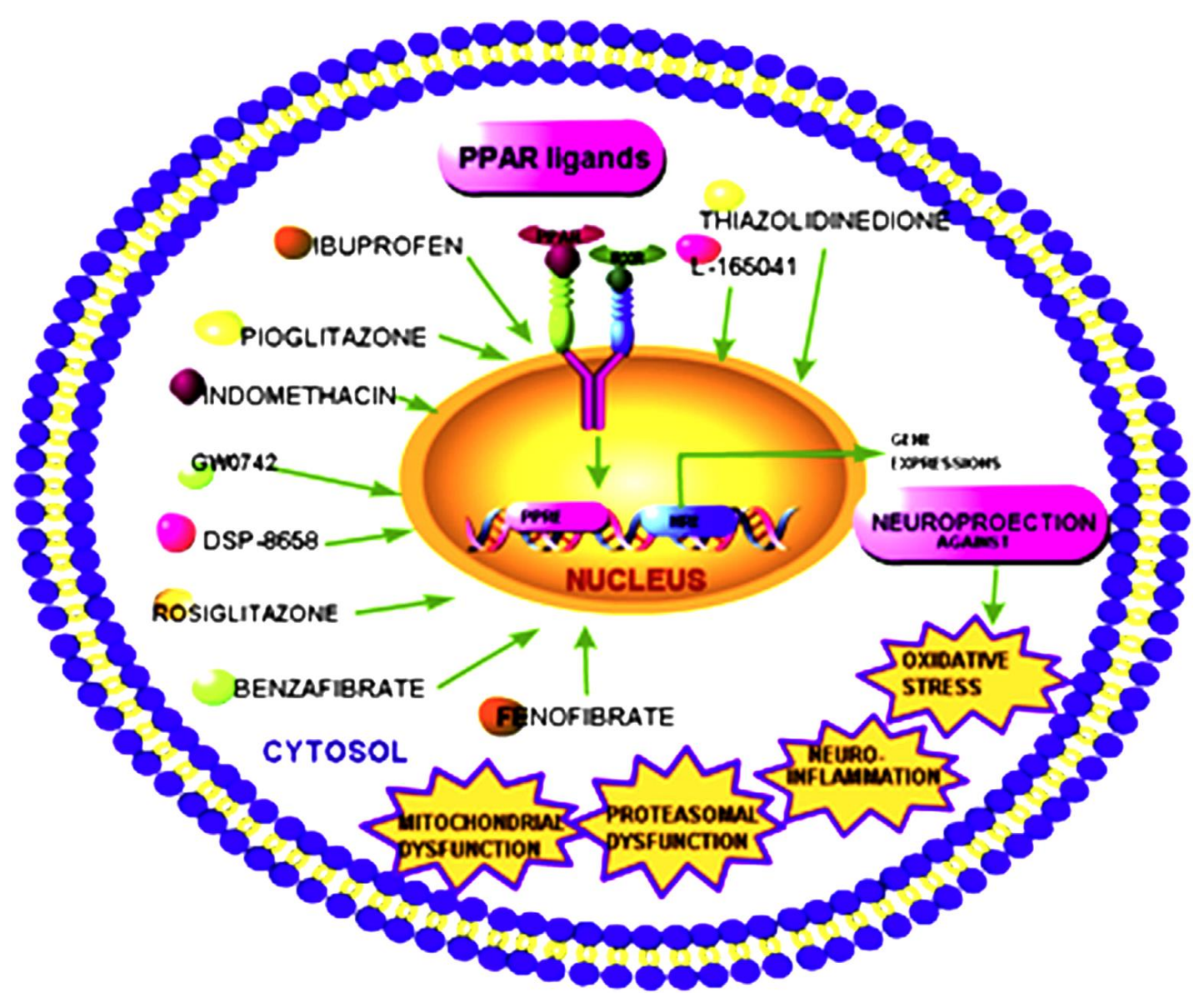

Figure 1: Ligands of PPARs and their cellular action (Adapted from Swati et al., 2017)

Prostaglandins or synthetic ligands like anti-diabetic thiazolidinediones activate PPAR- $\gamma$ which controls glucose metabolism by modulating insulin sensitivity (50). Non-steroidal antiinflammatory drugs are also weak agonists of PPAR- $\gamma$ and PPAR- $\alpha$. PPAR/ is one of the PPAR family's most commonly articulated members. Until recently, the function of PPAR- $\beta / \delta$ was unknown, but new research has revealed that it controls serum lipid profiles and fatty acid oxidation in muscle and adipose tissue, and thus plays a key role in lipid metabolism. Synthetic PPAR- $\beta / \delta$ ligands are currently in the preclinical stages of their development.

\section{PEROXISOME PROLIFERATOR-ACTIVATED RECEPTORS IN THE BRAIN}

The PPARs, induced by ligands known as transcription factors, belonging to the superfamily nuclear hormone receptors (NHR). As with other members of the NHR superfamily comprising steroid, thyroid, and retinoid receptors, during metazoan developments, it is assumed that PPARs are capable of binding to a ligand because they are present in all metazoan phyla. There are three different PPAR isotypes (PPAR- $\alpha$, PPAR- $\beta$, also called $\delta$, and PPAR- $\gamma$ ), which have been identified and are structurally uniform in different species.

Therefore, it appears that in rodents, foetal growth in a wide variety of cell types of ectodermal, mesodermal or endodermic embryos, PPAR- $\alpha$, PPAR- $\beta / \delta$, and PPAR $\gamma$ show unique spatialise 
tissue-dependent patterns of expression. PPARs have a role in various aspects of tissue differentiation and rodent growth such as adipose tissue, brain, placenta, and skin differentiation (reviewed in (51). It, therefore, appears that $\operatorname{PPAR}-\alpha, \beta / \delta$, and $\gamma$ are derived from an ancient Orphan receptor from a common PPAR gene, with wide ligand-binding specificity developed from a common PPAR gene with broad ligand-binding specificity, itself derived from the ancestral orphan receptor (reviewed in (52).

PPARs regulate genetic expression via several mechanisms and act as compulsory heterodimers with receptors for retinoid X. (RXRs). PPARs are composed of four domains, like the other members of the superfamily. The highly conserved DNA-binding domain and the zinc finger domain are common features of all NHR members. The C-terminal ligand-binding region by the hinge region is connected to the DNA binding domain. The E/F domain is responsible for dimerizing RXR PPARs, while the N-terminal domain is responsible for ligand-independent regulation of the receptor activity (53).

PPARs work to stimulate gene expression through the binding of their target genes with preserved DNA sequences, called peroxisome-proliferator response elements (PPREs). These heterodimers are physically linked to co-repressor complexes, which suppress gene transcription, in the absence of ligands (51). The NCor-containing complexes are discharged and replaced by co-activator complexes when the ligand is binding to the receptor. Then these coactivators are connected to the base transcription device and activate the transcription of these genes.

They also work to inhibit the expression of pro-inflammatory genes and do so by mechanisms not dependent on their ability to bind to DNA. Several mechanisms have been postulated for their trans repression activity and their selectiveness, none of which are completely satisfactory for NFKB-regulated genes (54). The new mechanism of PPAR- $\gamma$-mediated trans repression has recently been described by Glass and colleagues. NFאB-regulated inflammatory genes are maintained by their combination with $\mathrm{N}$-Cor that contains corepressor complexes in a repressed state. This complex is dissociated and gene expression is initiated after exposure to proinflammatory stimuli. PPAR- $\gamma$ agonists bind to the PPAR- $\gamma$ receptor, which is then modified by adding a sumoyl moiety to this ligand-receptor complex. This modified receptor binds to NC or complexes inhabiting $\mathrm{NF \kappa B}$ gene promoters, preventing the release of the corepressor complex, thereby preventing an inflammation of the gene $(55,56)$.

In response to dietary lipid intake, the PPARs act primarily as lipid sensors and control wholebody metabolism and direct the subsequent metabolism and storage (57). The prototypical family member, PPAR- $\alpha$, was initially identifying the subfamily of three related receptors as induced by 
proliferators of peroxisomes. Dietary lipids and their metabolites are the natural ligands of these receptors. Due to the relatively low-affinity interactions and the broad ligand specificity of the receptors, the specific ligands of the different receptors were hard to determine.

PPAR- $\alpha$ mainly acts to regulate energy homeostasis by stimulating fatty acid and cholesterol disintegration, leading to gluconeogenesis and a reduction in serum triglyceride levels. The receiver acts as a lipid sensor that binds and initiates the metabolism of the fatty acids. PPAR- $\alpha$ binds several fatty acids and natural lipid ligands including fats, eicosanoids. Its primary action is to encourage differentiation of adipocytes and to direct lipid metabolites into the tissue. PPAR- $\gamma$ works at the critical lipid and carbohydrate metabolism metabolic intersection. The activation of PPAR- $\gamma$ is linked to a decrease in serum glucose, which is likely to be the second effect of endocrine control. The development of specific PPAR- $\gamma$ agonists in the treatment of diabetes type 2 (58) resulted from this latter activity. PPAR- $\beta / \delta$ binds to and responds to fatty acids derived from VLDL, eicosanoids, including prostaglandin $A_{1}$ (59), and seems to have mainly an impact on fatty acid oxidation, especially in muscles.

Linking PPARs to their specific ligands leads to conformational changes that enable the release of co-repressors and the recruitment of co-activators. Although each PPAR isotype has its ligand binding properties, although the common ancient nuclear recipient can be attributed to a common nuclear receptor. Selective PPAR- $\gamma$ ligands are synthetically prescribed thiazolidinediones (TZDs) for the treatment of type II diabetes. Of course, eicosanoids and cyclopentenone prostaglandin 15d-PGJ2 are included in PPAR- $\gamma$ ligands. The TZDs including pioglitazone (Actos) and rosiglitazone (Avandia), approved for the treatment of type II diabetes by the Food and Drug Association (FDA), are the best-characterized PPAR- $\gamma$ agonists. Some of the PPAR- $\gamma$ agonists not based on TZD, such as GW78456 and others, have also been developed as a part of drug discovery.

PPAR- $\alpha$ ligands include fibrates that are commonly used in hypertriglyceridemia treatment and WY14,643 and GW7647 synthetic agonists developed for the same purpose. Prostacyclin PGI2, including GW0742, GW501516, and GW7842 are included in PPAR- $\beta / \delta$ agonists. Polyunsaturated fatty acids with different affinities and efficiencies can activate all three PPAR isotypes (60). Bernado and Minghetti have recently summarized an overview of the affinity of several natural and synthetic ligands (61).

\section{ROLE OF PEROXISOME PROLIFERATOR-ACTIVATED RECEPTORS IN PARKINSON'S DISEASE}


The pathological characteristic of idiopathic PD is the loss of dopaminergic neurons in the substantia nigra pars compacta $(\mathrm{SNpc})$. The production of reactive oxygen species and apoptosis can contribute significantly to neuronal cell degeneration through excitotoxicity, oxidative phosphorylation. The neurotoxin MPTP was experimentally used to assess the pathogenesis of PD. NO is a key MPTP toxicity mediator in the dopaminergic neurons (62-64). More studies have shown that the effect of neuroinflammation changes in PD (37) and MPTP-induced toxicity, accompanied by the astrocytic and micrographic expression of iNOS, may be crucial $(65,66)$.

Given that PPAR- $\gamma$ activations result in deep iNOS suppression in peripheral macrophages $(67,68)$ and neuroinflammation models $(69,70)$, synthetic PPAR- $\gamma$ ligands were treated to test the possibility that neuroprotection could be performed through PPAR- $\gamma$ mediation of antiinflammation effects. The pioglitazone therapy protected against DA-cell death induced by MPTP was discovered in the SNpc by Breidert and colleagues (71). Dehmer and colleagues have shown PPAR- $\gamma$ expression in striatum and substantial nigra in mouse and MPTP-treated mouse (72) have confirmed this finding. Pioglitazone also protected neurons from the MPTP-induced cell death from tyrosine hydroxylase-positive nigra. But striatal DA decrease was only partially prevented in both studies. The number of iNOS-positive cells in the striatum and SNPc was reduced and pioglitazone decreased by microglial and astrocyte activation $(73,74)$. Partly the removal of iNOS from treated MPTP mice by NFא-B related signal transduction could have been achieved, as pioglitazone therapy induced a striatal decrease in TNF- $\alpha$ and NFK-B. Similar data were obtained using the dopaminergic neurodegeneration induced by lipopolysaccharide and inflammation-driven rat model, in which pioglitazone reduces microglial inflammation effectively, attenuates oxidative stress, and restores mitochondrial function (75).

In addition to the PPAR- $\gamma$ agonist results observed with the MPTP model, PPAR- $\alpha$ shown to be protective from $\mathrm{TH}$-positive loss in SNpc and $\mathrm{TH}$ immunoreactivity in the striatum by tyrosine hydroxylase cells and preventative treatment of the mouse with PPAR- $\alpha$ agonist fenofibrate induced by MPTP. Clearly, another PPAR- $\alpha$ agonist in the same research failed to perform a bezafibrate, probably because the bezafibrate experiments contained a 10-fold lower drug concentration (76). Iwashita and colleagues have also shown that neuroprotective effects were exercised in PPAR- $\beta / \delta$ agonistic treatment of neuroblastoma cells stimulated by MPP+ (77).

Recent evidence has shown that NSAIDs, especially ibuprofen, can delay or prevent PD progression $(78,79)$. Since Ibuprofen passes the blood-brain barrier and is a potential agonist of PPAR- $\gamma(80)$, it is possible to have a beneficial effect on PD epidemiology from PPAR- $\gamma$ 
activation. In conjunction with these figures, treatment with PPAR- $\gamma$ agonists can provide a new treatment approach to PD.

\section{PEROXISOME PROLIFERATOR-ACTIVATED RECEPTORS AS A THERAPEUTIC OPTION FOR PARKINSON'S DISEASE}

It is well known that ROS formation, which leads to oxidative damage, microglial activation, mediated neuroinflammation, and mitochondrial dysfunction, causes degeneration of the DA neurons and eventually leads to cell mortality, apoptosis, and necrosis activation. Therefore, oxidative stress and mitochondrial dysfunction control can reduce neurodegeneration in PD (81). In some studies, in vitro and in vivo, PPAR agonists suggested potential neuroprotective effects (82-89).

In a mouse model of PD, pioglitazone, a PPAR- $\gamma$ agonist shielded dopaminergic neuronal cell bodies in the substantia nigra and its terminals in the striatum regions against MPTP, a potent mitochondrial neurotoxin (87). Dopaminergic cell loss and neurodegeneration in SNPc were prevented by oral dosing of pioglitazone before MPTP treatment (15 mg/kg i.p.) in an experimental animal model (90). In one of the studies also it was found that pioglitazone exerted a neuroprotective effect against MPTP-induced neuronal damage (88). Pioglitazone protects the brain from MPTP-induced neurotoxicity by inhibiting the activity of the enzyme monoamine oxidase-B due to blockage of the conversion of MPTP to MPP+ (91). Additionally, pioglitazone inhibits microglial activation, reduces inflammatory mediator levels, nitrotyrosine production in dopaminergic neurons, and significantly decreases the number of activated astrocytes in the striatum and substantia nigra regions of the brain (92). Numerous additional studies corroborate pioglitazone's anti-inflammatory and anti-apoptotic properties $(93,94)$. Pioglitazone was found to be neuroprotective against inflammation and dopaminergic neurodegeneration caused by intrastriatal injected lipopolysaccharide (LPS) in the rat brain (95). In another study, pioglitazone suppressed microglial activation and neuroinflammation induced by LPS (96). Pioglitazone inhibits oxidative stress and restores the mitochondrial capacity and function of dopaminergic neurons in the brain (97). Pioglitazone protects dopaminergic neurons from LPS-activated COX2 and prostaglandin E2-mediated microglial activation in co-cultures of dopaminergic neurons and astrocytes by interfering with other signalling pathways such as the Jun N-terminal kinase pathway, which is involved in COX-2 inhibition (98).

Another PPAR-agonist, Rosiglitazone was shown to be neuroprotective against MPTP by increasing PPARs activation in neurons (99). Activation of PPARs with rosiglitazone reverses mitochondrial dysfunction caused by the mitochondrial complex-I inhibitor rotenone and PINK1 
loss (100). MPTP lowers DA levels in the striatum and substantia nigra, which were contained in the PD model by rosiglitazone (101). Additionally, rosiglitazone was found to shield neuroblastoma cells from acetaldehyde, a mitochondrial function inhibitor (102). It protects neurons from oxidative stress and apoptosis caused by neurotoxin acetaldehyde (103). Rosiglitazone stimulates the expression of antioxidant enzymes and also controls the expression of apoptotic factors, reversing the neurotoxic effect of acetaldehyde (104). Additionally, rosiglitazone has been shown to protect human neuroblastoma cells from the toxicity caused by MPP, which results in mitochondrial dysfunction and oxidative stress (105). These findings provide strong evidence for the hypothesis that, in addition to their anti-inflammatory properties, PPAR agonists contribute to neuroprotection by controlling the expression of antioxidant enzymes and maintaining a balance between pro-and anti-apoptotic gene expression (103).

The hypothalamus is home to the PPAR- $\delta$ isoform, which is involved in maintaining brain homeostasis. PPAR- $\delta$ reduces inflammation, which protects against the production of dietinduced obesity (106). PPAR- $\delta$ is also known to be a powerful anti-inflammatory response regulator. Radiation-induced inflammatory responses in microglial cells, which are involved in inflammatory responses, are controlled by it (107). The PPAR- $\delta$ agonist L-165041 protected murine microglial cells from radiation-induced damage, including increased oxidative stress, COX-2, and MCP-1 expression, as well as increased levels of various cytokines and inflammatory mediators (108). By interacting with the p65 subunit, PPAR- $\delta$ inhibits NF-kB by trans-repression, preventing activation of the PKCa/MEK1/2/ERK1/2/AP-1 pathways (107). As a result, the findings suggest that PPAR activation can influence radiation-induced oxidative damage and inflammatory responses in microglial cells (109). By inhibiting caspase-3 activation, PPAR- $\delta$ agonists L-165041 and GW-501516 protect SH-SY5Y neuroblastoma cells from MPP+mediated apoptosis (110). These agonists also protect the striatum from MPTP-induced DA and metabolite depletion (111). Another PPAR- $\delta$ agonist, GW0742, has been shown to protect the spinal cord from damage $(112,113)$. PPAR- $\delta$ agonists reduce p38 MAP kinase, NF-kB activation, and COX-2 expression, resulting in reduced cell death (114).

Co-treatment with the PPAR- $\gamma$ antagonist GW-9662 and the agonist rosiglitazone has neuroprotective effects by inhibiting MPP+ formation as well as ROS generation (105). Many other PPAR- $\alpha$ agonists, such as fenofibrate and bezafibrate, have been studied in MPTP mouse models of PD (90). Fenofibrate has been found to protect dopaminergic neurons in the substantia nigra and to prevent the loss of tyrosine hydroxylase immunoreactivity in the striatum (90). Bezafibrate, on the other hand, had no major neuroprotective effect, which was attributed to the 
fact that the dose of bezafibrate was 10 times lower than that of fenofibrate (90). Many medications, such as indomethacin, naproxen, and fenoprofen, are non-steroidal antiinflammatory (NSAID) drugs that bind and activate PPAR- $\alpha$ and PPAR- $\gamma(106,107)$. Neuroprotection is provided by ibuprofen and indomethacin against neurodegenerative disorders such as PD (108). In mesencephalic cultures, ibuprofen at $0.1 \mathrm{mM}$ and acetaminophen at $1 \mathrm{mM}$ concentrations were found to reduce dopaminergic neurotoxicity induced by MPP+ (110). In a mouse model of PD, indomethacin also protects against MPTP-mediated neurotoxicity by reducing microglial activation and lymphocyte infiltration (110). Several other NSAIDs do not activate PPAR, but they still provide neuroprotection in MPTP-induced PD models by reducing oxidative damages and NF-kb expression via PPAR-independent mechanisms (111). It has been discovered that people who take these NSAIDs daily have a lower risk of developing PD than people who do not take them (112).

In human neuroblastoma SH-SY5Y cells, the PPAR- $\delta$ antagonist GSK0660 and the agonist GW0742 defend against MPP+-induced toxicity. In mice, intrastriatal infusion of GW0742 decreased MPTP-induced dopaminergic neuron loss (113). PPAR agonists are neuroprotective not only in PD, but also in other neurodegenerative diseases such as Alzheimer's disease, ALS, and Huntington's disease (114).

\section{CONCLUSION AND FUTURE DIRECTION}

Currently available medications for PD only offer symptomatic relief and do not stop or hinder the disease's progression. As a result, neuroprotective molecules are desperately needed to cure this crippling disease. In the pathophysiology of PD, many molecular pathways are involved, including oxidative stress, mitochondrial dysfunction, inflammation, and apoptosis. This may explain why existing therapeutics are unable to delay disease progression because they only modulate one target. Modification of many cellular and neuropathological pathways at the same time could be a more effective strategy for neuroprotection. This can be accomplished by combining many pharmacological agents or, more preferably, by using only one with pleiotropic implications. At the transcriptional level, PPAR agonists can induce gene expression and modulate multiple molecular pathways. As a result, PPAR agonists or drugs that function on transcription factor receptors may be used to treat neurodegenerative diseases. Further, exploratory, preclinical, and clinical investigations are essential using PPAR agonists to assess neuroprotective therapeutic benefits on disease progression as well as on onset of the disease. PPAR agonists' safety and tolerability concerns must also be discussed before large-scale clinical trials. Finally, realizing the molecular paths by which PPAR elicits neuroprotective effects can 
contribute to the development of a successful PD treatment. Prospects in terms of neuroprotection and neural repair include the development of new and more active PPAR activators, as well as the combined action of the various PPAR isoforms.

\section{REFERENCES}

1. Global, regional, and national burden of Parkinson's disease, 1990-2016: a systematic analysis for the Global Burden of Disease Study 2016. Lancet Neurol. 2018 Nov;17(11):939-53.

2. Espay AJ, Lang AE. Common Myths in the Use of Levodopa in Parkinson Disease: When Clinical Trials Misinform Clinical Practice. JAMA Neurol. 2017 Jun;74(6):633-4.

3. Seppi K, Ray Chaudhuri K, Coelho M, Fox SH, Katzenschlager R, Perez Lloret S, et al. Update on treatments for nonmotor symptoms of Parkinson's disease-an evidence-based medicine review. Mov Disord. 2019 Feb;34(2):180-98.

4. Coelho M, Ferreira JJ. Late-stage Parkinson disease. Nat Rev Neurol. 2012 Aug;8(8):435-42.

5. Poewe W, Mahlknecht P. The clinical progression of Parkinson's disease. Parkinsonism Relat Disord. 2009 Dec;15 Suppl 4:S28-32.

6. Beal MF. Mitochondria, oxidative damage, and inflammation in Parkinson's disease. Ann N Y Acad Sci. 2003 Jun;991:120-31.

7. Lin MT, Beal MF. Mitochondrial dysfunction and oxidative stress in neurodegenerative diseases. Nature. 2006 Oct;443(7113):787-95.

8. Anglade P, Vyas S, Javoy-Agid F, Herrero MT, Michel PP, Marquez J, et al. Apoptosis and autophagy in nigral neurons of patients with Parkinson's disease. Histol Histopathol. 1997 Jan;12(1):25-31.

9. McGeer PL, Itagaki S, Boyes BE, McGeer EG. Reactive microglia are positive for HLADR in the substantia nigra of Parkinson's and Alzheimer's disease brains. Neurology. 1988 Aug;38(8):1285-91.

10. Beal MF. Excitotoxicity and nitric oxide in Parkinson's disease pathogenesis. Ann Neurol [Internet]. 1998;44(3 Suppl 1):S110-4.

11. McNaught KSP, Belizaire R, Isacson O, Jenner P, Olanow CW. Altered proteasomal function in sporadic Parkinson's disease. Exp Neurol. 2003 Jan;179(1):38-46.

12. McNaught KSP, Belizaire R, Jenner P, Olanow CW, Isacson O. Selective loss of 20S proteasome alpha-subunits in the substantia nigra pars compacta in Parkinson's disease. Neurosci Lett. 2002 Jul;326(3):155-8. 
13. Thomas B, Beal MF. Parkinson's disease. Hum Mol Genet. 2007 Oct;16 Spec No:R18394.

14. Dexter DT, Carter CJ, Wells FR, Javoy-Agid F, Agid Y, Lees A, et al. Basal lipid peroxidation in substantia nigra is increased in Parkinson's disease. J Neurochem. 1989 Feb;52(2):381-9.

15. Sian J, Dexter DT, Lees AJ, Daniel S, Agid Y, Javoy-Agid F, et al. Alterations in glutathione levels in Parkinson's disease and other neurodegenerative disorders affecting basal ganglia. Ann Neurol. 1994 Sep;36(3):348-55.

16. Yoritaka A, Hattori N, Uchida K, Tanaka M, Stadtman ER, Mizuno Y. Immunohistochemical detection of 4-hydroxynonenal protein adducts in Parkinson disease. Proc Natl Acad Sci U S A. 1996 Apr;93(7):2696-701.

17. Floor E, Wetzel MG. Increased protein oxidation in human substantia nigra pars compacta in comparison with basal ganglia and prefrontal cortex measured with an improved dinitrophenylhydrazine assay. J Neurochem. 1998 Jan;70(1):268-75.

18. Jenner P. Oxidative mechanisms in nigral cell death in Parkinson's disease. Mov Disord. 1998;13 Suppl 1:24-34.

19. Beal MF. Oxidatively modified proteins in aging and disease. Free Radic Biol Med. 2002 May;32(9):797-803.

20. Fukae J, Takanashi M, Kubo S, Nishioka K, Nakabeppu Y, Mori H, et al. Expression of 8-oxoguanine DNA glycosylase (OGG1) in Parkinson's disease and related neurodegenerative disorders. Acta Neuropathol. 2005 Mar;109(3):256-62.

21. Simon DK, Lin MT, Zheng L, Liu G-J, Ahn CH, Kim LM, et al. Somatic mitochondrial DNA mutations in cortex and substantia nigra in aging and Parkinson's disease. Neurobiol Aging. 2004 Jan;25(1):71-81.

22. Beal MF. Mitochondria take center stage in aging and neurodegeneration. Ann Neurol. 2005 Oct;58(4):495-505.

23. Langston JW, Ballard P, Tetrud JW, Irwin I. Chronic Parkinsonism in humans due to a product of meperidine-analog synthesis. Science. 1983 Feb;219(4587):979-80.

24. Bindoff LA, Birch-Machin M, Cartlidge NE, Parker WDJ, Turnbull DM. Mitochondrial function in Parkinson's disease. Vol. 2, Lancet (London, England). England; 1989. p. 49.

25. Schapira AH, Cooper JM, Dexter D, Clark JB, Jenner P, Marsden CD. Mitochondrial complex I deficiency in Parkinson's disease. J Neurochem. 1990 Mar;54(3):823-7. 
26. Haas RH, Nasirian F, Nakano K, Ward D, Pay M, Hill R, et al. Low platelet mitochondrial complex I and complex II/III activity in early untreated Parkinson's disease. Ann Neurol. 1995 Jun;37(6):714-22.

27. Schapira AH V. Mitochondrial dysfunction in Parkinson's disease. Cell Death Differ. $2007 \mathrm{Jul} ; 14(7): 1261-6$.

28. Gu M, Cooper JM, Taanman JW, Schapira AH. Mitochondrial DNA transmission of the mitochondrial defect in Parkinson's disease. Ann Neurol. 1998 Aug;44(2):177-86.

29. Betarbet R, Sherer TB, MacKenzie G, Garcia-Osuna M, Panov A V, Greenamyre JT. Chronic systemic pesticide exposure reproduces features of Parkinson's disease. Nat Neurosci. 2000 Dec;3(12):1301-6.

30. Testa CM, Sherer TB, Greenamyre JT. Rotenone induces oxidative stress and dopaminergic neuron damage in organotypic substantia nigra cultures. Brain Res Mol Brain Res. 2005 Mar;134(1):109-18.

31. Luoma PT, Eerola J, Ahola S, Hakonen AH, Hellström O, Kivistö KT, et al. Mitochondrial DNA polymerase gamma variants in idiopathic sporadic Parkinson disease. Neurology. 2007 Sep;69(11):1152-9.

32. Liang C-L, Wang TT, Luby-Phelps K, German DC. Mitochondria mass is low in mouse substantia nigra dopamine neurons: implications for Parkinson's disease. Exp Neurol. $2007 \mathrm{Feb} ; 203(2): 370-80$.

33. Hunot S, Brugg B, Ricard D, Michel PP, Muriel MP, Ruberg M, et al. Nuclear translocation of NF-kappaB is increased in dopaminergic neurons of patients with parkinson disease. Proc Natl Acad Sci U S A. 1997 Jul;94(14):7531-6.

34. Mogi M, Harada M, Kondo T, Mizuno Y, Narabayashi H, Riederer P, et al. bcl-2 protein is increased in the brain from parkinsonian patients. Neurosci Lett. 1996 Sep;215(2):1379.

35. Hartmann A, Hunot S, Michel PP, Muriel MP, Vyas S, Faucheux BA, et al. Caspase-3: A vulnerability factor and final effector in apoptotic death of dopaminergic neurons in Parkinson's disease. Proc Natl Acad Sci U S A. 2000 Mar;97(6):2875-80.

36. Mogi M, Kondo T, Mizuno Y, Nagatsu T. p53 protein, interferon-gamma, and NFkappaB levels are elevated in the parkinsonian brain. Neurosci Lett. 2007 Feb;414(1):94-7.

37. Nagatsu T, Mogi M, Ichinose H, Togari A. Changes in cytokines and neurotrophins in Parkinson's disease. J Neural Transm Suppl. 2000;(60):277-90. 
38. Mogi M, Togari A, Kondo T, Mizuno Y, Komure O, Kuno S, et al. Caspase activities and tumor necrosis factor receptor R1 (p55) level are elevated in the substantia nigra from parkinsonian brain. J Neural Transm. 2000;107(3):335-41.

39. Zhang W, Wang T, Pei Z, Miller DS, Wu X, Block ML, et al. Aggregated alphasynuclein activates microglia: a process leading to disease progression in Parkinson's disease. FASEB J Off Publ Fed Am Soc Exp Biol. 2005 Apr;19(6):533-42.

40. Dawson TM, Dawson VL. Rare genetic mutations shed light on the pathogenesis of Parkinson disease. J Clin Invest. 2003 Jan;111(2):145-51.

41. McNaught KS, Olanow CW, Halliwell B, Isacson O, Jenner P. Failure of the ubiquitinproteasome system in Parkinson's disease. Nat Rev Neurosci. 2001 Aug;2(8):589-94.

42. Miwa H, Kubo T, Suzuki A, Nishi K, Kondo T. Retrograde dopaminergic neuron degeneration following intrastriatal proteasome inhibition. Neurosci Lett. 2005 May;380(1-2):93-8.

43. Blanquart C, Barbier O, Fruchart JC, Staels B, Glineur C. Peroxisome proliferatoractivated receptors: regulation of transcriptional activities and roles in inflammation. $\mathrm{J}$ Steroid Biochem Mol Biol. 2003 Jun;85(2-5):267-73.

44. Bishop-Bailey D. Peroxisome proliferator-activated receptors in the cardiovascular system. Br J Pharmacol. 2000 Mar;129(5):823-34.

45. Buchan KW, Hassall DG. PPAR agonists as direct modulators of the vessel wall in cardiovascular disease. Med Res Rev. 2000 Sep;20(5):350-66.

46. Berger JP, Akiyama TE, Meinke PT. PPARs: therapeutic targets for metabolic disease. Trends Pharmacol Sci. 2005 May;26(5):244-51.

47. Desvergne B, Wahli W. Peroxisome proliferator-activated receptors: nuclear control of metabolism. Endocr Rev. 1999 Oct;20(5):649-88.

48. Escriva H, Delaunay F, Laudet V. Ligand binding and nuclear receptor evolution. Bioessays. 2000 Aug;22(8):717-27.

49. Kersten S, Wahli W. Peroxisome proliferator activated receptor agonists. EXS. 2000;89:141-51.

50. Jones DC, Manning BM, Daynes RA. A role for the peroxisome proliferator-activated receptor alpha in T-cell physiology and ageing immunobiology. Proc Nutr Soc. 2002 Aug;61(3):363-9. 
51. Ghisletti S, Huang W, Ogawa S, Pascual G, Lin M-E, Willson TM, et al. Parallel SUMOylation-dependent pathways mediate gene- and signal-specific transrepression by LXRs and PPARgamma. Mol Cell. 2007 Jan;25(1):57-70.

52. Ogawa S, Lozach J, Benner C, Pascual G, Tangirala RK, Westin S, et al. Molecular determinants of crosstalk between nuclear receptors and toll-like receptors. Cell. 2005 Sep;122(5):707-21.

53. Michalik L, Auwerx J, Berger JP, Chatterjee VK, Glass CK, Gonzalez FJ, et al. International Union of Pharmacology. LXI. Peroxisome proliferator-activated receptors. Pharmacol Rev. 2006 Dec;58(4):726-41.

54. Willson TM, Lambert MH, Kliewer SA. Peroxisome proliferator-activated receptor gamma and metabolic disease. Annu Rev Biochem. 2001;70:341-67.

55. Barish GD. Peroxisome proliferator-activated receptors and liver $\mathrm{X}$ receptors in atherosclerosis and immunity. J Nutr. 2006 Mar;136(3):690-4.

56. Krey G, Braissant O, L'Horset F, Kalkhoven E, Perroud M, Parker MG, et al. Fatty acids, eicosanoids, and hypolipidemic agents identified as ligands of peroxisome proliferatoractivated receptors by coactivator-dependent receptor ligand assay. Mol Endocrinol. 1997 Jun;11(6):779-91.

57. Bernardo A, Minghetti L. PPAR-gamma agonists as regulators of microglial activation and brain inflammation. Curr Pharm Des. 2006;12(1):93-109.

58. Cimini A, Bernardo A, Cifone MG, Di Marzio L, Di Loreto S. TNFalpha downregulates PPARdelta expression in oligodendrocyte progenitor cells: implications for demyelinating diseases. Glia. 2003 Jan;41(1):3-14.

59. Saluja I, Granneman JG, Skoff RP. PPAR delta agonists stimulate oligodendrocyte differentiation in tissue culture. Glia. 2001 Mar;33(3):191-204.

60. Cristiano L, Bernardo A, Cerù MP. Peroxisome proliferator-activated receptors (PPARs) and peroxisomes in rat cortical and cerebellar astrocytes. J Neurocytol. 2001 Aug;30(8):671-83.

61. Farioli-Vecchioli S, Moreno S, Cerù MP. Immunocytochemical localization of acyl-CoA oxidase in the rat central nervous system. J Neurocytol. 2001 Jan;30(1):21-33.

62. Hantraye P, Brouillet E, Ferrante R, Palfi S, Dolan R, Matthews RT, et al. Inhibition of neuronal nitric oxide synthase prevents MPTP-induced parkinsonism in baboons. Nat Med. 1996 Sep;2(9):1017-21. 
63. Przedborski S, Jackson-Lewis V, Yokoyama R, Shibata T, Dawson VL, Dawson TM. Role of neuronal nitric oxide in 1-methyl-4-phenyl-1,2,3,6-tetrahydropyridine (MPTP)induced dopaminergic neurotoxicity. Proc Natl Acad Sci U S A. 1996 May;93(10):456571.

64. Schulz JB, Matthews RT, Muqit MM, Browne SE, Beal MF. Inhibition of neuronal nitric oxide synthase by 7-nitroindazole protects against MPTP-induced neurotoxicity in mice. J Neurochem. 1995 Feb;64(2):936-9.

65. Dehmer T, Lindenau J, Haid S, Dichgans J, Schulz JB. Deficiency of inducible nitric oxide synthase protects against MPTP toxicity in vivo. J Neurochem. 2000 May;74(5):2213-6.

66. Liberatore GT, Jackson-Lewis V, Vukosavic S, Mandir AS, Vila M, McAuliffe WG, et al. Inducible nitric oxide synthase stimulates dopaminergic neurodegeneration in the MPTP model of Parkinson disease. Nat Med. 1999 Dec;5(12):1403-9.

67. Colville-Nash PR, Qureshi SS, Willis D, Willoughby DA. Inhibition of inducible nitric oxide synthase by peroxisome proliferator-activated receptor agonists: correlation with induction of heme oxygenase 1. J Immunol. 1998 Jul;161(2):978-84.

68. Ricote M, Li AC, Willson TM, Kelly CJ, Glass CK. The peroxisome proliferatoractivated receptor-gamma is a negative regulator of macrophage activation. Nature. 1998 Jan;391(6662):79-82.

69. Heneka MT, Gavrilyuk V, Landreth GE, O’Banion MK, Weinberg G, Feinstein DL. Noradrenergic depletion increases inflammatory responses in brain: effects on IkappaB and HSP70 expression. J Neurochem. 2003 Apr;85(2):387-98.

70. Breidert T, Callebert J, Heneka MT, Landreth G, Launay JM, Hirsch EC. Protective action of the peroxisome proliferator-activated receptor-gamma agonist pioglitazone in a mouse model of Parkinson's disease. J Neurochem. 2002 Aug;82(3):615-24.

71. Dehmer T, Heneka MT, Sastre M, Dichgans J, Schulz JB. Protection by pioglitazone in the MPTP model of Parkinson's disease correlates with I kappa B alpha induction and block of NF kappa B and iNOS activation. J Neurochem. 2004 Jan;88(2):494-501.

72. Hunter RL, Dragicevic N, Seifert K, Choi DY, Liu M, Kim H-C, et al. Inflammation induces mitochondrial dysfunction and dopaminergic neurodegeneration in the nigrostriatal system. J Neurochem. 2007 Mar;100(5):1375-86.

73. Kreisler A, Gelé P, Wiart J-F, Lhermitte M, Destée A, Bordet R. Lipid-lowering drugs in the MPTP mouse model of Parkinson's disease: fenofibrate has a neuroprotective effect, 
whereas bezafibrate and HMG-CoA reductase inhibitors do not. Brain Res. 2007 Mar;1135(1):77-84.

74. Chen H, Jacobs E, Schwarzschild MA, McCullough ML, Calle EE, Thun MJ, et al. Nonsteroidal antiinflammatory drug use and the risk for Parkinson's disease. Ann Neurol. 2005 Dec;58(6):963-7.

75. Chen H, Zhang SM, Hernán MA, Schwarzschild MA, Willett WC, Colditz GA, et al. Nonsteroidal anti-inflammatory drugs and the risk of Parkinson disease. Arch Neurol. 2003 Aug;60(8):1059-64.

76. Lehmann JM, Lenhard JM, Oliver BB, Ringold GM, Kliewer SA. Peroxisome proliferator-activated receptors alpha and gamma are activated by indomethacin and other non-steroidal anti-inflammatory drugs. J Biol Chem. 1997 Feb;272(6):3406-10.

77. Bassaganya-Riera J, Reynolds K, Martino-Catt S, Cui Y, Hennighausen L, Gonzalez F, et al. Activation of PPAR gamma and delta by conjugated linoleic acid mediates protection from experimental inflammatory bowel disease. Gastroenterology. 2004 Sep;127(3):77791.

78. Chaturvedi RK, Flint Beal M. Mitochondrial diseases of the brain. Free Radic Biol Med. 2013 Oct; 63:1-29.

79. Mounsey RB, Martin HL, Nelson MC, Evans RM, Teismann P. The effect of neuronal conditional knock-out of peroxisome proliferator-activated receptors in the MPTP mouse model of Parkinson's disease. Neuroscience. 2015 Aug;300:576-84.

80. Falcone R, Florio TM, Di Giacomo E, Benedetti E, Cristiano L, Antonosante A, et al. $\operatorname{PPAR} \beta / \delta$ and $\gamma$ in a rat model of Parkinson's disease: possible involvement in PD symptoms. J Cell Biochem. 2015 May;116(5):844-55.

81. Martinez AA, Morgese MG, Pisanu A, Macheda T, Paquette MA, Seillier A, et al. Activation of PPAR gamma receptors reduces levodopa-induced dyskinesias in 6OHDA-lesioned rats. Neurobiol Dis. 2015 Feb;74:295-304.

82. Carta AR, Simuni T. Thiazolidinediones under preclinical and early clinical development for the treatment of Parkinson's disease. Expert Opin Investig Drugs. 2015 Feb;24(2):219-27.

83. Pisanu A, Lecca D, Mulas G, Wardas J, Simbula G, Spiga S, et al. Dynamic changes in pro- and anti-inflammatory cytokines in microglia after PPAR- $\gamma$ agonist neuroprotective treatment in the MPTPp mouse model of progressive Parkinson's disease. Neurobiol Dis. 2014 Nov;71:280-91. 
84. Barbiero JK, Santiago RM, Persike DS, da Silva Fernandes MJ, Tonin FS, da Cunha C, et al. Neuroprotective effects of peroxisome proliferator-activated receptor alpha and gamma agonists in model of parkinsonism induced by intranigral 1-methyl-4-phenyl1,2,3,6-tetrahyropyridine. Behav Brain Res. 2014;

85. Swanson CR, Du E, Johnson DA, Johnson JA, Emborg ME. Neuroprotective Properties of a Novel Non-Thiazoledinedione Partial PPAR- $\gamma$ Agonist against MPTP. PPAR Res. 2013;2013:582809.

86. Zhang X, Rodriguez-Galán MC, Subleski JJ, Ortaldo JR, Hodge DL, Wang J-M, et al. Peroxisome proliferator-activated receptor-gamma and its ligands attenuate biologic functions of human natural killer cells. Blood. 2004 Nov;104(10):3276-84.

87. Chaturvedi RK, Beal MF. PPAR: a therapeutic target in Parkinson's disease. J Neurochem. 2008 Jul;106(2):506-18.

88. Cowell RM, Blake KR, Inoue T, Russell JW. Regulation of PGC-1alpha and PGC1alpha-responsive genes with forskolin-induced Schwann cell differentiation. Neurosci Lett. 2008 Jul;439(3):269-74.

89. Carroll CB, Zeissler M-L, Hanemann CO, Zajicek JP. $\Delta^{9}$-tetrahydrocannabinol ( $\left.\Delta^{9}-\mathrm{THC}\right)$ exerts a direct neuroprotective effect in a human cell culture model of Parkinson's disease. Neuropathol Appl Neurobiol. 2012 Oct;38(6):535-47.

90. Pinto M, Nissanka N, Peralta S, Brambilla R, Diaz F, Moraes CT. Pioglitazone ameliorates the phenotype of a novel Parkinson's disease mouse model by reducing neuroinflammation. Mol Neurodegener. 2016 Apr;11:25.

91. Xing B, Xin T, Hunter RL, Bing G. Pioglitazone inhibition of lipopolysaccharideinduced nitric oxide synthase is associated with altered activity of p38 MAP kinase and PI3K/Akt. J Neuroinflammation. 2008 Jan;5:4.

92. Ulusoy GK, Celik T, Kayir H, Gürsoy M, Isik AT, Uzbay TI. Effects of pioglitazone and retinoic acid in a rotenone model of Parkinson's disease. Brain Res Bull. 2011 Jul;85(6):380-4.

93. Luptak I, Balschi JA, Xing Y, Leone TC, Kelly DP, Tian R. Decreased contractile and metabolic reserve in peroxisome proliferator-activated receptor-alpha-null hearts can be rescued by increasing glucose transport and utilization. Circulation. 2005 Oct;112(15):2339-46.

94. Corona JC, de Souza SC, Duchen MR. PPAR $\gamma$ activation rescues mitochondrial function from inhibition of complex I and loss of PINK1. Exp Neurol. 2014 Mar;253:16-27. 
95. Carta AR, Frau L, Pisanu A, Wardas J, Spiga S, Carboni E. Rosiglitazone decreases peroxisome proliferator receptor- $\gamma$ levels in microglia and inhibits TNF- $\alpha$ production: new evidences on neuroprotection in a progressive Parkinson's disease model. Neuroscience. 2011 Oct;194:250-61.

96. Jung TW, Lee JY, Shim WS, Kang ES, Kim SK, Ahn CW, et al. Rosiglitazone relieves acute ethanol-induced hangover in Sprague-Dawley rats. Alcohol Alcohol. 2006;41(3):231-5.

97. Lee YM, Choi JS, Kim MH, Jung MH, Lee YS, Song J. Effects of dietary genistein on hepatic lipid metabolism and mitochondrial function in mice fed high-fat diets. Nutrition. 2006 Sep;22(9):956-64.

98. Jung TW, Lee JY, Shim WS, Kang ES, Kim SK, Ahn CW, et al. Rosiglitazone protects human neuroblastoma SH-SY5Y cells against MPP+ induced cytotoxicity via inhibition of mitochondrial dysfunction and ROS production. J Neurol Sci. 2007 Feb;253(1-2):5360.

99. Kocalis HE, Turney MK, Printz RL, Laryea GN, Muglia LJ, Davies SS, et al. Neuronspecific deletion of peroxisome proliferator-activated receptor delta (PPAR $\delta$ ) in mice leads to increased susceptibility to diet-induced obesity. PLoS One. 2012;7(8):e42981.

100. Schnegg CI, Kooshki M, Hsu F-C, Sui G, Robbins ME. PPAR $\delta$ prevents radiation-induced proinflammatory responses in microglia via transrepression of $\mathrm{NF}-\kappa \mathrm{B}$ and inhibition of the PKC $\alpha / \mathrm{MEK} 1 / 2 / \mathrm{ERK} 1 / 2 / \mathrm{AP}-1$ pathway. Free Radic Biol Med. 2012 May;52(9):1734-43.

101. Lim H-J, Lee S, Park J-H, Lee K-S, Choi H-E, Chung K-S, et al. PPAR delta agonist L-165041 inhibits rat vascular smooth muscle cell proliferation and migration via inhibition of cell cycle. Atherosclerosis. 2009 Feb;202(2):446-54.

102. Sadeghian M, Marinova-Mutafchieva L, Broom L, Davis JB, Virley D, Medhurst $\mathrm{AD}$, et al. Full and partial peroxisome proliferation-activated receptor- $\gamma$ agonists, but not $\delta$ agonist, rescue of dopaminergic neurons in the 6-OHDA parkinsonian model is associated with inhibition of microglial activation and MMP expression. J Neuroimmunol. 2012 May;246(1-2):69-77.

103. Iwashita A, Muramatsu Y, Yamazaki T, Muramoto M, Kita Y, Yamazaki S, et al. Neuroprotective efficacy of the peroxisome proliferator-activated receptor delta-selective agonists in vitro and in vivo. J Pharmacol Exp Ther. 2007 Mar;320(3):1087-96. 
104. Benetti E, Mastrocola R, Rogazzo M, Chiazza F, Aragno M, Fantozzi R, et al. High sugar intake and development of skeletal muscle insulin resistance and inflammation in mice: a protective role for PPAR- $\delta$ agonism. Mediators Inflamm. 2013;2013:509502.

105. Gill N, Bijjem KR V, Sharma PL. Anti-inflammatory and anti-hyperalgesic effect of all-trans retinoic acid in carrageenan-induced paw edema in Wistar rats: involvement of peroxisome proliferator-activated receptor- $\beta / \delta$ receptors. Indian $J$ Pharmacol. 2013;45(3):278-82.

106. Esposito E, Paterniti I, Meli R, Bramanti P, Cuzzocrea S. GW0742, a highaffinity PPAR $-\delta$ agonist, mediates protection in an organotypic model of spinal cord damage. Spine (Phila Pa 1976). 2012 Jan;37(2):E73-8.

107. Martin HL, Mounsey RB, Mustafa S, Sathe K, Teismann P. Pharmacological manipulation of peroxisome proliferator-activated receptor $\gamma(\operatorname{PPAR} \gamma)$ reveals a role for anti-oxidant protection in a model of Parkinson's disease. Exp Neurol. 2012 Jun;235(2):528-38.

108. Brown PJ, Smith-Oliver TA, Charifson PS, Tomkinson NC, Fivush AM, Sternbach DD, et al. Identification of peroxisome proliferator-activated receptor ligands from a biased chemical library. Chem Biol. 1997 Dec;4(12):909-18.

109. Jiang Q, Heneka M, Landreth GE. The role of peroxisome proliferator-activated receptor-gamma (PPARgamma) in Alzheimer's disease: therapeutic implications. CNS Drugs. 2008;22(1):1-14.

110. Carrasco E, Casper D, Werner P. Dopaminergic neurotoxicity by 6-OHDA and MPP+: differential requirement for neuronal cyclooxygenase activity. J Neurosci Res. $2005 \mathrm{Jul} ; 81(1): 121-31$.

111. Kurkowska-Jastrzebska I, Babiuch M, Joniec I, Przybyłkowski A, Członkowski A, Członkowska A. Indomethacin protects against neurodegeneration caused by MPTP intoxication in mice. Int Immunopharmacol. 2002 Jul;2(8):1213-8.

112. Cuzzocrea S, Bruscoli S, Mazzon E, Crisafulli C, Donato V, Di Paola R, et al. Peroxisome proliferator-activated receptor-alpha contributes to the anti-inflammatory activity of glucocorticoids. Mol Pharmacol. 2008 Feb;73(2):323-37.

113. Martin HL, Mounsey RB, Sathe K, Mustafa S, Nelson MC, Evans RM, et al. A peroxisome proliferator-activated receptor- $\delta$ agonist provides neuroprotection in the 1- 
methyl-4-phenyl-1,2,3,6-tetrahydropyridine model of Parkinson's disease. Neuroscience. 2013 Jun;240:191-203.

114. Kapadia R, Yi J-H, Vemuganti R. Mechanisms of anti-inflammatory and neuroprotective actions of PPAR-gamma agonists. Front Biosci. 2008 Jan;13:1813-26.

AJPHR is

Peer-reviewed monthly

Rapid publication

Submit your next manuscript at editor@ajphr.com / editor.ajphr@gmail.com 